Abstract G441(P) Table 1 Summary of reported care plan preference for each component

\begin{tabular}{|c|c|c|c|c|c|c|}
\hline & \multicolumn{3}{|c|}{ Parents/Teachers } & \multicolumn{3}{c|}{ School Nurses } \\
\cline { 2 - 7 } & Cardiff & BSAC & Chi squared & Cardiff & BSAC & Chi Squared \\
\hline Child identity & 28 & 30 & 0.8645 & 24 & 9 & 0.0013 \\
\hline Contact details & 40 & 20 & 0.0012 & 19 & 10 & 0.0619 \\
\hline Allergy type & 25 & 30 & 0.4910 & 18 & 15 & 0.6500 \\
\hline $\begin{array}{c}\text { Mild allergy } \\
\text { info }\end{array}$ & 26 & 20 & 0.3700 & 20 & 12 & 0.1095 \\
\hline $\begin{array}{c}\text { Severe allergy } \\
\text { info }\end{array}$ & 29 & 28 & 1 & 21 & 18 & 0.6549 \\
\hline $\begin{array}{c}\text { How to use } \\
\text { 5pipen }\end{array}$ & 16 & 35 & 0.0015 & 24 & 7 & 0.0002 \\
\hline $\begin{array}{c}\text { What to do } \\
\text { after using } \\
\text { Egipen }\end{array}$ & 34 & 17 & 0.0049 & 17 & 18 & 1 \\
\hline Consent & 60 & 0 & 0.0001 & 39 & 1 & 0.0001 \\
\hline $\begin{array}{c}\text { Overall } \\
\text { Preference }\end{array}$ & $\mathbf{2 3}$ & $\mathbf{4 0}$ & $\mathbf{0 . 0 0 6 7}$ & $\mathbf{2 6}$ & $\mathbf{2}$ & $\mathbf{0 . 0 0 0 1}$ \\
\hline
\end{tabular}

parental consent. Teachers/ parents also preferred it for post Epipen advice. A revised national version with clearer contact details, better information on what to do after Epipen is administered and parental consent is required.

\section{G442(P) WHAT DO LOOKED AFTER YOUNG PEOPLE THINK ABOUT THE SPECIALIST HEALTH SERVICES THEY USE?}

${ }^{1}$ E Sunderland, ${ }^{2} \mathrm{~K}$ Wood, ${ }^{3} \mathrm{~S}$ Barwick. ${ }^{1}$ Neonatal Unit, Homerton University Hospital Trust, London, UK; ${ }^{2}$ Neonatal Unit, City Hospitals Sunderland Foundation Trust, Sunderland, UK; ${ }^{3}$ Bishop Auckland General Hospital, County Durham and Darlington NHS Foundation Trust, Durham, UK

\subsection{6/archdischild-2015-308599.396}

Aim There is limited research concerning the experiences, preferences and priorities of looked after children and young people (LACYP) relating to healthcare. LACYP have higher rates of physical, developmental and mental health problems than their peers, with worse longer-term outcomes. This study aims to capture young people's views on health and mental health services specifically for LACYP.

Method A questionnaire was created, incorporating issues identified as important to LACYP in existing literature, and modified with input from involved health and social care professionals and a LACYP participation group. Two LACYP health services and one LACYP mental health service were investigated over a four month period. All LACYP, aged 12 years and over, who attended for an initial or review health assessment or for specialist mental health services were given a questionnaire to complete anonymously in relation to their appointment.

Results 136 questionnaires were completed. Mean age of participants was 15.1 years (range 12-18), with equal numbers of males and females. 92\% were glad they had attended their appointment, 99\% felt listened to, 95\% thought professionals were easy to talk to and $97 \%$ considered their views were taken seriously. $8 \%$ were not offered an opportunity to speak with the practitioner alone, but $73 \%$ of this group would not have wanted to do so. $7 \%$ worried about who would see the information given. Free text comments corresponded closely to key themes regarded by LACYP as important in existing literature;
LACYP want to talk to professionals who listen and have an ability to get things done.

Conclusion It is clear the majority felt these services helped them; this is particularly relevant to health appointments where LACYP are not referred with a specific problem, but for statutory review. Recommendations include all LACYP being offered opportunities to speak with practitioners alone and ensuring confidentiality is discussed at the beginning of appointments. Acting on the results of this study forms the first step in ensuring local services meet the needs of LACYP more effectively.

\section{G443(P) EVALUATING USER EXPERIENCE IN COMMUNITY PAEDIATRICS USING THE FRIENDS AND FAMILY TEST (FFT)}

G Bhusari, K Banerjee, S Thomas. Community Paediatrics, North East London Foundation Trust, Grays, UK

\subsection{6/archdischild-2015-308599.397}

Aims The FFT survey is only due to be rolled out nationally to all community and mental health trusts in 2015 by DOH. Our aim was to proactively use the FFT to evaluate child and young person (CYP) and carer's experience about community paediatric clinic appointments, in a variety of settings. This would be helpful towards obtaining timely feedback from CYP and parents, about the quality of care offered by community paediatricians and identify areas for improvement.

Method The Friend and Family Test (FFT) is a single question survey which asks patients and carers whether they would recommend the NHS service they have received, to friends and family who need similar treatment or care. The survey was conducted prospectively on all patients seen by community paediatricians during a 6 -week period from 1st July until 15th August 2014. At the end of each clinic consultation, the form was handed to eligible CYP and carers for completion. CYP aged 8 years and over were included and those with moderate to severe learning difficulty were excluded. Carers of CYP from 0-19 years' age range were included. A marked box was kept for them to drop the completed form in at the reception, before leaving the clinic. All the completed forms were sent to the audit department for further evaluation. 